\title{
aniki
}

Revista Portuguesa da Imagem em Movimento

Portuguese Journal of the Moving Image

\section{Archivo, Memoria y Resignificación: Acercamientos al cine de reapropiación en México}

\section{J. Pablo Romo Álvarez}

Universidad Veracruzana, México

famosoodie@gmail.com

\section{Elissa J. Rashkin}

Universidad Veracruzana, México

erashkin@uv.mx

https://orcid.org/0000-0003-1223-777X

RESUMEN Este artículo explora las posibilidades analíticas del estudio del cine mexicano desde la desaparición y/o fragmentación de los archivos primordiales, para llegar posteriormente al ejercicio experimental de la reconstrucción. Nos avalamos del creciente corpus de historias trabajadas sobre y desde los márgenes de la cultura y la comunicación, donde los huecos y silencios hablan tanto como los hechos verificables. Partimos de la pérdida de la mayor parte del archivo cinematográfico mexicano del periodo silente, notando que, aun en periodos posteriores, la ausencia física de películas extraviadas o destruidas es exacerbada por varios tipos de olvido. Sin embargo, al generalizarse el acceso a la tecnología de producción, llegan a abundarse los indicios desligados de contextos identificables y, por lo tanto, desasociados de la memoria tanto individual como colectiva. Son estas imágenes incompletas, dispersas y residuales que el cine de reapropiación utiliza para plantear una suerte de reordenamiento simbólico: un ejercicio crítico de indagación acerca de la imagen fílmica, sus soportes materiales y los dispositivos que le dan origen. Para ejemplificar los argumentos, analizamos los cortometrajes Fantasmas del adiós de Ximena Cuevas (2019) y iAllá vienen! de Ezequiel Reyes (2018), ambos realizados a partir de archivos familiares, que permiten ilustrar las diferentes estrategias posibles para la resignificación de las memorias individuales y colectivas en el cine actual de reapropiación.

PALABRAS CLAVE Reapropiación; cine experimental; cine temprano; cine mexicano; historia cinematográfica.

El trabajo historiográfico con el cine generalmente parte de un artefacto o conjunto de artefactos fílmicos que el análisis procura 
contextualizar en términos de un tiempo y un lugar más o menos específicos, para versar sobre los vectores culturales ahí expresados o latentes. Aquí, sin embargo, nos interesa explorar las posibilidades analíticas del estudio del cine mexicano desde la ausencia, para llegar posteriormente al ejercicio experimental de la reconstrucción. Nos avalamos del creciente corpus de historias trabajadas sobre y desde los márgenes de la cultura y la comunicación, donde los huecos y silencios hablan tanto como los hechos verificables a través del archivo. ${ }^{1}$

Si partimos desde el cine temprano en el país - desde la llegada del aparato de los hermanos Lumière en 1896 hasta el inicio del cine sonoro- tomamos consciencia de la importancia de analizar los artefactos tangibles en un contexto caracterizado por la desaparición y fragmentación del corpus. La pérdida de la mayor parte de este archivo significa que sólo podemos conocer esta primera producción a través de datos extratextuales, aunque la labor de investigadores como Aurelio de los Reyes (1981, 1986, 1987, 1993, 2016), Ángel Miquel (2000, 2003, 2005, 2012), Juan Felipe Leal (2012, 2019), Leal, Eduardo Barraza y Alejandra Jablonska (1993), María Luisa Amador y Jorge Ayala Blanco (2009), Ortiz Monasterio (2010), Emilio García Riera (1992) y otros durante varias décadas ha generado una admirable bibliografía basada en este procedimiento. ${ }^{2}$ Aun en periodos posteriores, de los cuales hay una representación fílmica más extensa, la ausencia física de las películas extraviadas o destruidas, su decadencia o condición fragmentada, es exacerbada por varios tipos de olvido: los rollos, extraídos de su contexto, se despojan de sus significados originales. ${ }^{3}$ Paradójicamente, mientras se generaliza el

\footnotetext{
${ }^{1}$ Aunque nuestro interés se centra en el cine mexicano, vale la pena reconocer la nueva y prometedora línea en los estudios cinematográficos que están redefiniendo no sólo las formas de análisis sino los objetos de estudio en sí. Por ejemplo, Haidee Wasson (2020) argumenta que la experiencia de ver y escuchar cine se extiende mucho más allá de las salas dedicadas al medio, y analiza el uso de proyectores portátiles en situaciones diversas como la escuela, la industria y el frente de batalla en las guerras del siglo XX. Katherine Groo (2019) examina la práctica de producir películas etnográficas a partir del contexto más que del objeto, subrayando entre otras cosas que la mayoría de estos artefactos visuales ni llegaron ni fueron dirigidos a un público espectador.

${ }^{2}$ Incluimos aquí las fechas de algunas publicaciones representativas; varias de ellas pertenecen a series de múltiples volúmenes, y las que citamos no agotan la extensa obra de cada uno de los autores citados.

${ }^{3}$ Así como la historia gráfica anclada en las fotografías del Archivo Casasola llegó a constituir la memoria oficial del país compuesto principalmente, a decir de John Mraz, de "machos, mitos y mentiras" (2003, 203), las imágenes fijas y en movimiento empleadas para ilustrar documentales de corte histórico tienden a reforzar supuestos que, en realidad, surgieron después. En el caso prolífero de la Revolución mexicana, por ejemplo, el hecho de saber el desenlace de cada etapa del conflicto es lo que facilita la construcción de héroes y villanos, dejando atrás la incertidumbre (y las posibles simpatías personales del camarógrafo) presente al momento de la filmación. Véase Pérez Montfort (2011, 33-34).
} 
acceso a la tecnología de producción en la segunda mitad del siglo XX en adelante, llegan a abundarse los indicios desligados de los contextos identificables y por lo tanto, desasociados de la memoria tanto individual como colectiva. Son estas imágenes incompletas, dispersas y residuales el material con el que algunos cineastas construyen sus propias obras a partir de un reordenamiento simbólico que no pretende funcionar como una estrategia de reconstrucción histórica, sino, por el contrario, que se presenta como un ejercicio crítico de indagación acerca de la imagen, sus soportes materiales y los dispositivos que le dan origen. ${ }^{4}$ En algunos estudios se ha abordado esta práctica cinematográfica desde el concepto de found footage, término que se traduce como "metraje encontrado" y que hace alusión al encuentro fortuito de material fílmico susceptible a ser reciclado y manipulado para nuevos fines. Alicia Serrano (2013, 16), por ejemplo, considera al found footage como una técnica que permite crear películas a partir de fragmentos de metraje ajeno, los cuales se presentan en una nueva disposición que los dota de nuevos sentidos distintos de su intención original. No obstante, el concepto resulta algo problemático al aplicarse a una categoría de obras cuyo común denominador sigue siendo el reempleo de imágenes y sonidos, pero que varían en sus procedimientos, metodologías y propósitos. Por lo tanto, han surgido otras denominaciones: cine de remontaje, cine reciclado, cine de desmontaje, entre otros. En las páginas que siguen, privilegiamos el término reapropiación, por las implicaciones que conlleva más allá del nivel formal. En el cine de reapropiación, lo que se mira adquiere un nuevo sentido no solo porque haya sido alterado o manipulado, sino porque alguien ha generado un nuevo canal de entendimiento a partir del cuestionamiento de lo visible.

Este tipo de práctica audiovisual implica un desplazamiento del foco de la mirada: más allá de concentrarse en lo que habita en la imagen, propone una interpretación desde lo que no está presente, es decir,

\footnotetext{
${ }^{4}$ En "Escribir historia con imágenes. Breve relato de tres experiencias" (2011), Pérez Montfort muestra que la reconstrucción histórica es un ejercicio creativo de interpretación que bien puede ser crítico; sin embargo, el uso más prevalente y convencional es el que emplea el metraje encontrado al servicio de la historia oficial o canónica. En el ámbito del centenario revolucionario, la publicidad en torno a La historia en la mirada (José Ramón Mikelajáuregui 2010) enfatizó la autenticidad de los materiales incorporados, aunque la narración desvía poco del guion ya conocido de los eventos. En cambio, en Los rollos perdidos de Pancho Villa (2003), Gregorio Rocha documenta su búsqueda de una película desaparecida de 1914, encontrando en el camino otros datos e imágenes que conlleva a una reflexión sobre la ausencia y la distancia como aspectos fundamentales del conocimiento histórico.
} 
desde aquello que transita fuera de los bordes de las imágenes y sirve como estructura simbólica para su interpretación en un contexto específico. Las imágenes-fragmento son rastros de una memoria incompleta que nos obliga a considerar lo faltante como un aspecto fundamental. Por ende, este artículo examina las implicaciones de hacer análisis cinematográfico desde estos diversos espacios historiográficos-ontológicos de ausencia y resignificación. Ocupando el caso mexicano como escenario de exploración, partimos del periodo más temprano del cine en el país, para llegar, de manera más dialéctica que cronológica, a algunos ejemplos de la práctica de reapropiación en nuestros días.

\section{De fuentes y cenizas}

Plantear la ausencia como condición primordial que estructura el análisis es una propuesta que comparten investigadores en diferentes campos historiográficos, particularmente con respecto a sujetos excluidos o marginados del archivo como institución: las mujeres (en general), las sexualidades no heteronormativas, las comunidades indígenas, la infancia, entre otros. En su estudio sobre pérdidas y recuperación de archivos en América Latina, Carlos Aguirre y Javier Villa-Flores escriben $(2015,11)$ :

Fuentes (o su ausencia) [...] dan forma a nuestros proyectos de investigación de maneras que son a veces imprevisibles, pero siempre importantes. Pero una "falta de fuentes" usualmente contiene una historia interesante y muy importante en sí, ya que es, por lo general, el resultado de luchas de poder específicas que provienen de tensiones políticas, sociales, culturales e institucionales. (traducción nuestra)

En el caso del cine mexicano, la frase "cenizas de la historia" en el título del libro citado cobra sentido literal: el incendio en la Cineteca Nacional el 24 de marzo de 1982 que provocó por lo menos cinco muertos, numerosos heridos, caos y pánico general — de acuerdo con la cobertura en la prensa-, también destruyó una vasta cantidad de material fílmico: patrimonio irrecuperable cuya misma fragilidad 
material, ligada a la volatilidad del nitrato de plata, resultó a la vez cómplice y víctima del desastre (Soto 2020). ${ }^{5}$ Un corto-circuito cerca de donde se almacenaba esta sustancia altamente combustible parece haber producido la explosión y consecuente destrucción del edificio. No obstante, como institución gubernamental, bajo el mando de Margarita López Portillo, directora de Radio, Televisión y Cinematografía y hermana del entonces presidente de la república, los rumores en torno al incendio tejieron un discurso de negligencia o incluso una posible intencionalidad. ${ }^{6}$ Dicho discurso ejemplifica las "tensiones políticas, sociales, culturales e institucionales" que Aguirre y Villa-Flores señalan como siempre presentes en las historias de la destrucción, desaparición o carencia de archivos.

Sin embargo, más allá de este suceso catastrófico, se puede afirmar que la escasez de evidencia fílmica, en el primer periodo de la historia del medio, es una condición generalizada en América Latina y en el mundo. ${ }^{7}$ Al reconocer la pérdida de un aproximado $90 \%$ del metraje del cine temprano en México, por ejemplo, entendemos el significado latente del término cine mudo: mudo no por la ausencia del sonido grabado, sino por el hecho de su aniquilación. Quienes intentamos estudiar este periodo de la producción fílmica en el país haremos bien en recordar lo que aconseja Georges Didi-Huberman en el libro titulado, precisamente, Arde la imagen: "cada vez que ponemos los ojos en una imagen, deberíamos pensar en las condiciones que impidieron su destrucción, su desaparición. Es tan fácil destruir imágenes, en cada época ha sido algo tan normal" $(2012,18)$. La efímera existencia de la Filmoteca de la Secretaría de Educación Pública, fundada en 1942 por la actriz, cronista y promotora de cine Elena Sánchez Valenzuela y desmantelada sólo seis años después por motivos a todas luces

\footnotetext{
${ }^{5}$ La nota de Jessica Soto en El Universal incluye la cobertura original del suceso por Francisco Leyva y Guillermo Valencia en el mismo periódico el 25 de marzo de 1982.

${ }^{6}$ En el documental Los rollos perdidos (2012), el realizador Gibrán Bazán relaciona la confusión alrededor del incendio con la probable presencia en la Cineteca de unos 14 mil pies de celuloide filmados por el gobierno mexicano durante la masacre de estudiantes y otros civiles por fuerzas estatales en la plaza de Tlatelolco, Ciudad de México, el 2 de octubre de 1968.

${ }^{7}$ Tanto Andrea Cuarterolo $(2017,419)$ como Aurelio de los Reyes y David Wood $(2016,9)$ citan a dos encuestas coordinadas por Maria Rita Galvão, una en 1988 y otra en 2005, que confirmaron la existencia de $7 \%$ y $15 \%$ respectivamente de la producción fílmica iberoamericana anterior a los años treinta. El aumento revela la atención brindada a este periodo a partir de las celebraciones del centenario del cine, por parte de investigadores, archivos y medios de difusión; aun así, las cifras acusan mucho más la pérdida del acervo que su recuperación.
} 
personalistas y políticos (Torres San Martín 2018, 173-191), también es sintomático de esta condición "normal” de la desaparición.

En parte por esta escasez de materia prima de análisis, y en parte por las perspectivas evolucionistas que, de acuerdo con Genaro Talens y Santos Zunzunegui (1998, 9-38), seguían informando los estudios del cine aun cuando tales perspectivas habían sido profundamente cuestionadas en el campo histórico en general, los metros filmados durante las primeras décadas del medio fueron relegados a la prehistoria, como si su única función fuera ensayar los pasos que posteriormente permitiría la existencia del cine sonoro, dramático, de presentación teatral y de larga extensión. Los fragmentos disponibles para el análisis sirven para marcar pasos: aquí empieza el montaje, aquí la puesta en escena, aquí cierto tipo de actuación, a pesar de que ni los productores ni los espectadores del temprano siglo XX podían haber compartido esa visión futurista de lo que, para ellos, era artefacto lúdico y didáctico, "moderno" acorde a su propio presente.

Para el caso mexicano, la interpretación teleológica se ha centrado, además, en la idea de que el cine temprano, sobre todo durante y después de la Revolución, necesariamente compartiera el mismo nacionalismo que llegaría a su melodramático fulgor en la llamada Época de Oro. Los pocos largometrajes que han sobrevivido, como Tepeyac (1917) o hasta cierto punto El automóvil gris (1919), parecerían sostener esta hipótesis, pero sólo superficialmente: digamos, ni a primera vista, pues al revisarlos, vemos de inmediato que su parentesco es otro. En un artículo sobre el asunto, David Wood observa que "el dar por hecho una tradición cinematográfica nacional puede constituir de por sí un acto ideológico"; y nota que, si bien Tepeyac fue aclamada por la crítica de su época como un hito generador de orgullo nacionalista, proyectaba un discurso distinto del de los melodramas posteriores, enfocado en la reivindicación del "tiempo mítico" y religioso ante la modernidad ejemplificada en la Constitución revolucionaria y su afirmación del estado laico (Wood 2011, 32-36).

Además, Wood subraya la excepcionalidad de la película, rechazando la noción de un posible corpus unificado ya que "la producción cinematográfica mexicana [de la época], al menos en cuanto el cine argumental, fue irregular y frecuentemente artesanal, y para los años 20 la producción local llegó a sufrir gravemente frente a la abrumadora competencia del cine estadounidense" (2011, 36). Como él y otros investigadores han mostrado con precisión a través de la prensa y otros 
artefactos paratextuales, lo que consumían los espectadores en el temprano siglo $\mathrm{XX}$ no fue una dieta de producciones dramáticas referentes a cuestiones nacionales, sino un difuso banquete de cine extranjero entremezclado con vistas locales (y luego noticieros), música y espectáculo en vivo: experiencias situadas multisensoriales, imposibles de recrear con exactitud de manera retrospectiva.

La labor de historiadores como Wood, Aurelio de los Reyes, Patricia Torres, Ángel Miquel, Andrea Cuarterolo y muchas personas más está de- y reconstruyendo la historia del cine temprano desde ángulos ya menos positivistas, a través del planteamiento de preguntas distintas de las que predominaban a lo largo del siglo XX. ${ }^{8}$ Sin embargo, como suele pasar con los estudios realizados en ámbitos especializados, el impacto de estas investigaciones aún no se nota en el imaginario social, donde el cine nacional de antaño genera poca pasión. Las vistas filmadas durante el Porfiriato y la Revolución han sido apropiadas tantas veces para ilustrar documentales históricos, o bien recreadas para dotar de autenticidad producciones dramáticas posteriores, que se han vuelto una especie de fondo común, invisible por "conocido", y por ende, tan "aburrido" como cualquier otro producto de la historia patria: un himno nacional cuya letra no deja de ser entonada, de modo obligatorio, por el solo hecho de ser incomprendida. ${ }^{9}$

Agregado a este concepto de pérdida asociada con la fragmentación y destrucción de las evidencias materiales, hay que considerar otros vacíos, más espectrales quizás, y a su vez constituyentes de campos de

\footnotetext{
${ }^{8}$ Claro es que esta ampliación no se limita a los primeros años del cine en el país. Lo que hace tiempo era una bibliografía modesta se ha multiplicado exponencialmente, agregando objetos de estudio como el cine aficionado, experimental y comercial o complejizando los temas clásicos (el melodrama, el Nuevo Cine) desde el análisis social, intertexual y transnacional. Una parte significativa de esta producción se ha publicado fuera de México; como botón de muestra está el libro coordinado por Olivia Cosentino y Brian Price (2022), con capítulos sobre lucha libre, "chili westerns", melodrama racial y cine familiar, entre otros temas. Cosentino y Price enmarcan su proyecto como "el Santo contra la Cineteca Nacional", en un intento evidente de repensar el cine mexicano fuera de los cánones asociados con la teoría del auteur y más vinculado con los públicos. En relación dialéctica con ese propósito, encontramos la antología bilingüe coordinada por Jesse Lerner y Luciano Piazza (2017) en el marco del proyecto Pacific Standard Time: $L A / L A$ llevado a cabo en California en 2017-2018. Este libro documenta un panorama de cine de arte y de lucha política, en general poco conocido; en el capítulo "Experimentación visual en Super 8", Álvaro Vázquez Mantecón versa sobre México, analizando las experiencias de Manuel Álvarez Bravo, Teo Hernández y Silvia Gruner (2017, 26-49).

${ }^{9}$ Esta reflexión proviene en parte de la revisión de muchos artefactos audiovisuales que surgieron de la conmemoración del bicentenario de la independencia nacional y el centenario de la revolución maderista en 2010 y, por otra parte, de la experiencia de impartir la materia Gramática del cine silente en la Universidad Veracruzana, amén de la observación cotidiana del tratamiento que recibe el cine temprano en el actual ecosistema mediático, sobre todo prensa digital y redes sociales.
} 
poder y representación. Volviendo al planteamiento de DidiHuberman, podemos variarlo para referir a la relación entre presencia y ausencia: cada vez que ponemos los ojos en una imagen, deberíamos pensar en las condiciones que conllevaron la creación de esta imagen en particular, ante la infinidad de posibilidades no concretadas. Es decir, el dirigir la cámara hacia determinado personaje - un Porfirio Díaz, un Emiliano Zapata, digamos - significa no dirigirla hacia otros sujetos, o bien incluirlos, pero como una masa anónima, cuya identidad genera poco interés y con el tiempo se vuelve imposible confirmar. La mujer, el campesino, algún bebe en brazos... incluso ciertos personajes filmados a propósito, por "pintorescos", se vuelven fantasmas que "hablan", si acaso, de la mirada del camarógrafo, enmarcado en un mercado de producción, circulación y consumo asociado con el circuito de viajes, la expansión ferrocarrilera, la exploración de las regiones a través del folclore y un incipiente turismo cultural.

El archivo, en este sentido, puede existir y a la vez carecer de legibilidad. La identificación de personas y situaciones, localidades o temporalidades, incluso la simple pregunta “¿por qué se filmó esto?” no siempre se pueden responder. Además, y fiel a la idea de los primeros inventores en torno al cine como medio para resguardar una copia fiel de las personas después de su muerte y así lograr una especie de inmortalidad, están los sujetos ya desaparecidos: quienes en algún momento fueron apreciados por su talento, su protagonismo en alguna esfera de actividad humana, o simplemente, en el cine casero y familiar, como seres queridos dignos de registrar. Con el paso del tiempo, estos sujetos, al igual que las lápidas carcomidas y engullidas por la maleza en un cementerio viejo, caen en el olvido: su imagen sujeta a la descomposición, el almacenamiento genérico desatendido - cual fosa común-, incluso tirada a la basura, o en el mejor de casos, puesta en circulación al lado de otras "cosas viejas", de manera desligada en absoluto de su origen particular.

Todas estas categorías de ausencia pueden asociarse, por supuesto, con la reconstrucción de memorias personales y colectivas, pero también con la reapropiación, la resignificación que parte de la no memoria y conlleva a la construcción de nuevas memorias. Desde el inicio del siglo XXI, varias pesquisas se han enfocado en las prácticas artísticas reapropiacionistas, tanto desde la teoría de la comunicación y los nuevos medios, como en los estudios cinematográficos, la teoría del arte, la antropología y los estudios visuales. A continuación, repasamos 
este campo teórico, para seguir después al análisis de dos casos provenientes del cine actual de reapropiación.

\section{De la ausencia a la re-presentación}

El teórico francés Nicolás Bourriaud utiliza el concepto de "arte de postproducción" para referirse a la creación artística que tiene como propósito apoderarse de los códigos de la vida y la cultura: no para producir nuevas imágenes, sino, más bien, para hacerlos funcionar de otra manera, a partir de la creación de protocolos de uso de los modos de representación. Con esto, se desplaza la cuestión acerca de la originalidad creativa hacia la administración de lo que ya existe (2004, 14). Para Bourriaud, la pregunta artística ya no se encuentra en lo "nuevo" que se pueda crear, sino en qué se puede crear con lo ya existente, de tal manera que los artistas actuales "programan" formas antes de componerlas $(2004,8)$.

Juan Luis Martín, por su parte, considera que la práctica reapropiacionista en el arte conforma uno de los parámetros fundamentales de lo postmoderno, que supone la radicalización de estrategias como la cita o el plagio (2001, 7). Sin embargo, advierte la necesidad de distinguir entre dos tipos de apropiación: la positiva o afirmativa, relacionada con el mundo de la publicidad y la industria cultural, en que la reutilización de imágenes y sonidos deviene en una estrategia mercadológica que neutraliza su potencial subversivo, convirtiéndolo en trivial e intrascendente; y la crítica, cuyo ejercicio implica un espíritu de revisión y relectura sobre lo dado, enfocando la atención en los marcos de la imagen y no en la imagen misma. Esto implica un desplazamiento del foco de atención desde el centro de la imagen hacia aquello que la sostiene y la hace posible (Martín 2001, 7; véase también Vilches 2009, 4), así como a las ausencias que la rodean. ${ }^{10} \mathrm{Al}$ desplazar las imágenes y reubicarlas en nuevos contextos, se establecen otras relaciones y significaciones que permiten reflexionar acerca de las condiciones institucionales atrás de su existencia, circulación e incorporación a la cultura.

\footnotetext{
${ }^{10}$ Ausencias que pueden incluir, como escribe Rivera Garza, "the material traces of those who were there, and those who are here as I write; specters, apparitions, memories, accompaniment" $(2020,53)$.
} 
Como escriben Manuel Hernández y Martín, la práctica reapropiacionista no se avoca a entender las imágenes como representaciones de la realidad, sino que también pregunta desde dónde y de qué manera han sido producidas y en qué contexto se han hecho presentes $(1998,50)$. Así, las imágenes son desbordadas para entenderlas por lo que muestran, pero también por lo que las sostiene; es decir, aquello que no es visible pero que igual es imagen; de forma que los autores concuerdan con el planteamiento de Jacques Rancière $(2008,82)$ que la imagen no se define sólo por la presentación de lo visible. Siguiendo esta línea de reflexión, se puede afirmar que la práctica reapropiacionista en el arte contemporáneo funciona como un ejercicio de cuestionamiento de las imágenes, haciendo hincapié, más que en lo visible, en las condiciones institucionales: es decir, en las configuraciones políticas, sociales y culturales que las validan y las incorporan al sistema de la cultura, haciéndolas, por un lado, sobrevivir al olvido, el abandono y la destrucción, y por otro, otorgándoles una significación que se acomoda a una narrativa cultural, civilizatoria y epistémica que invisibiliza las estructuras de poder que las hace posibles y para las que también funciona. Si esta narrativa procura suturar heridas y ocultar ausencias, la reapropiación llama la atención hacia ellas para convertirlas en pregunta abierta.

Como ya se mencionó, en el ámbito cinematográfico, estas prácticas basadas en la revisión, reordenamiento, intervención y reempleo de imágenes y sonidos preexistentes han sido catalogadas bajo el concepto de found footage, en clara referencia al objet trouvé (objeto encontrado) surrealista. En el surrealismo, los objetos cotidianos eran modificados material o conceptualmente para reorientar su significado y dotarlos de valores estéticos más allá de su función o contexto original. Si bien el término found footage remite a esta vanguardia artística, teóricos como Emilio Bernini $(2010,25)$ han ubicado los orígenes de este cine también en el constructivismo pictórico ruso y las teorías de montaje cinematográfico de Serguei Eisenstein y Dziga Vertov. No olvidemos que el cine de reapropiación es, ante todo, un cine basado en el montaje, en el que el guion y la puesta en escena se desplazan a la sala de edición.

Actualmente, la noción de found footage resulta problemática para describir la diversidad de técnicas, procedimientos y orígenes de las imágenes reutilizadas; pues, como explica Gloria Vilches (2009, 6), éstas ya no provienen siempre de un encuentro azaroso, sino que son 
resultado de un proceso de búsqueda y selección, por lo cual la idea de "encontrar" (found) abandona su carácter fortuito para transformarse en una intención específica. ${ }^{11}$ Por otra parte, el concepto footage sugiere el trabajo con material fílmico, lo que hoy en día ya no representa un imperativo, pues muchas de las prácticas contemporáneas no se limitan al uso exclusivo de lo fílmico, sino que también emplean una diversidad de formatos y tecnologías.

Al respecto, Eduardo Russo $(2016,22)$ señala que, si bien durante buena parte del siglo XX los materiales de found footage fueron fílmicos, en las últimas décadas, con el surgimiento de la televisión y el video, el espectro de imágenes reutilizadas se amplió hacia la indagación de una galaxia audiovisual de la cual, a pesar de su heterogeneidad abrumadora, es posible hacer cine. Por su parte, Antonio Weinrichter $(1998,2009)$ sostiene que la reapropiación es un género y a la vez una técnica que puede ser utilizada de manera parcial o total en distintas producciones cinematográficas, ya sea ficción, documental o experimental. Weinrichter considera que los ejercicios de reempleo de material visual y sonoro que se dan en el campo creativo del cine experimental rebasan los usos simplistas de la representación, la referencialidad, la ironía y el homenaje, para procurar discusiones más profundas sobre la imagen como depositario semántico.

En este contexto, la imagen transgrede su valor como recurso ilustrativo para posicionarse como forma contenedora de múltiples significados, los cuales, a través de su reordenamiento y manipulación, abren la posibilidad a nuevas interpretaciones y asociaciones significantes (Elsaesser 2015, 120). Los materiales reapropiados no son utilizados de manera afirmativa - como prueba de la realidad, mímesis o representación-, sino que son sometidas a operaciones técnicas y simbólicas que indagan en su arquitectura para alterar, agregar o quitar algo con el propósito de "desnudar" el proyecto oculto que el/la artista reapropiacionista ha identificado en ellos (Wolf 2010, 14).

Si bien el cine de reapropiación se caracteriza por construirse principalmente a través del montaje, la búsqueda, revisión y selección

\footnotetext{
${ }^{11}$ También se pueden imaginar películas que parten de una noción de pérdida, el "lost footage", como sugiere el ejemplo mencionado del documental de Gregorio Rocha, Los rollos perdidos de Pancho Villa.
} 
de materiales son asimismo momentos fundamentales (Noriega 2012, 138). El espíritu de indagación orienta a las y los artistas a escudriñar en diferentes espacios con el propósito de rescatar materiales que poseen un valor simbólico y/o conceptual más allá de lo que puedan mostrar. Esta voluntad de rescate - ante los huecos ya mencionados en el archivo colectivo- alberga una dimensión de preservación que no logra concretarse en su totalidad ya que, según Wolf $(2010,12)$, la/el cineasta reapropiacionista no pretende conservar los materiales; más bien procura hacer algo con ellos, evitando su archivación museística y su congelamiento. De esta manera, la práctica reapropiacionista se diferencia del coleccionismo al proponer una "alteración" del material que permita una reescritura sobre, con y desde las imágenes, es decir, la creación de una nueva película a partir de otra ya existente (Wolf 2010, 13). Se trata de imprimirle una mirada personal al material ajeno a través de un desplazamiento que las saque del flujo de la historia para instalarlas en otro espacio, en una nueva sintaxis (Trerotola 2010, 52).

Las imágenes reapropiadas en el cine suelen proceder de múltiples fuentes que establecen diversas condiciones de acceso, reproducción y reutilización, lo que, a su vez, puede condicionar la manera en que las y los realizadores acceden al material. Archivos institucionales, colecciones privadas, fotografías y/o películas huérfanas encontradas en algún mercado de antigüedades, archivos y colecciones digitalizadas puestas en circulación a través de internet, así como archivos familiares anónimos o relacionados directamente con la/el artista, son algunas fuentes cuya enumeración constata de lo heterogéneo de los materiales reapropiados, su procedencia y función original. Esto se traduce en una extensa gama de posibilidades creativas que no se limita a una fórmula concreta, sino que representa un campo en constante transformación, un territorio mutante plagado de desvíos para los cuales no existen mapas (Noriega 2012, 138).

Ingrid Guardiola (2015) señala que, ante la nueva retórica que establece el cine de reapropiación, resulta ineludible reconsiderar los elementos sintácticos del montaje a fin de entenderlos no sólo como recursos formales, sino como productores de sentido. La autora divide su propuesta en dos grupos: uno al que denomina "parada y repetición", que refiere a una interrupción o corte de la continuidad de la imagenmovimiento para producir en el espectador un efecto de extrañamiento y reflexión; y el otro, que responde más a una serie de estrategias metodológicas, mediante las cuales las imágenes se ponen en relación 
(32-45). En el primero se utilizan recursos como el congelamiento de la imagen, la repetición o la incorporación de fotogramas en negro o blanco que remiten a la ausencia de lo visible, mientras que en el segundo se emplean técnicas como la sobreimpresión, la pantalla partida, la multipantalla y la imagen dialéctica. Esta última se refiere al montaje de fragmentos heterogéneos y descontextualizados para romper con la continuidad temporal y discursiva de la obra, posibilitando la actualización del pasado a través de un proceso de resemantización. Regresaremos sobre estos recursos creativos más adelante, en el análisis de cortometrajes; primero, cabe elucidar unos puntos relacionados con el universo de lo familiar.

\section{La reapropiación de lo familiar}

Entre el cúmulo de imágenes que circulan en el paisaje visual contemporáneo, las imágenes familiares, domésticas y personales constituyen un cuerpo visual que, durante las últimas décadas, ha sido muy utilizado por creadores alrededor del mundo, destacándose como una tendencia no exclusiva al ámbito de la experimentación audiovisual de reapropiación, sino también en el cine documental u otras variantes como el cine autobiográfico o el cine ensayo. Este fenómeno coincide con el interés que los archivos familiares han generado en la historiografía durante el mismo periodo, debido a su utilidad para los estudios de la cotidianidad, de la familia y de los sujetos excluidos de la historia tradicional.

En un artículo al respecto, David Wood explica que el término "archivo familiar" contiene dos significaciones: por una parte, refiere a la acumulación de recuerdos y narraciones de experiencias subjetivas repetidas dentro de un entorno familiar; por otra, alude a los documentos (gráficos, sonoros, visuales, fílmicos, videográficos) preservados por familiares, o bien, descartados por ellos y posteriormente rescatados o adquiridos por coleccionistas (Wood 2014, 100). Susan Sontag plantea que el primer uso popular de la fotografía fue la imagen familiar: con la incorporación de la cámara fotográfica al ámbito privado, cada familia podía construir una crónica de sí misma que daba testimonio de la fortaleza de sus lazos, puesto que, en buena medida, el propósito de estas imágenes ha sido mantener los vínculos íntimos entre los miembros del grupo, haciendo visible un pasado común que permite la creación y recreación de la epopeya 
familiar, la preservación del recuerdo de felicidad y plenitud (2010, 18). Para Walter Benjamin, el valor ritual de la imagen se concentra en el retrato fotográfico porque éste permite convocar el recuerdo de los seres amados, lejanos o fallecidos - los ausentes-, otorgándole a estas imágenes una "belleza melancólica" incomparable en la que la expresión de un rostro humano funciona como el último refugio, desde donde el aura de las imágenes resiste a su inevitable desaparición (2003, 58).

Las imágenes familiares, fijas y/o en movimiento, conforman un esfuerzo por retener el tiempo, por atrapar los momentos y evitar, en la medida de lo posible, su desaparición. Contribuyen asimismo a la conformación del mito familiar, una especie de leyenda que se recrea, en buena medida, a través de las imágenes contribuyendo a la conformación de la identidad compartida de la familia. Como toda narrativa, el mito familiar también es un ejercicio de montaje, en que lo visible es ordenado con el propósito de alinear el tiempo en una perspectiva progresiva que presenta al parentesco como una estructura identitaria sólida: cualquier imagen que no contribuya a su consolidación es descartada, desechada o borrada.

Según Roger Odin (citado en Lins 2017, 47-48), los estudios cinematográficos han excluido los filmes domésticos al considerarlos productos corrientes, carentes de técnica y realizados como simple distracción, lo que los vuelve tediosos. Sin embargo, al tiempo que la historiografía del medio expande para abarcar categorías de cine no canónicos, algunos creadores audiovisuales se han dedicado a trabajar con y desde imágenes familiares. Ya sea en el cine documental o desde la experimentación audiovisual, esta tendencia, explica Wood (2014, 113), se corresponde con una revaloración teórica del cine, ahora centrada no en la fidelidad "positiva" (documental-referencial) de lo fílmico, sino en las verdades emotivas que pueda contener y revelar, es decir, en lo que existe pero que se mantiene oculto. De esta manera, las/los realizadores buscan, a través de diversos mecanismos y estrategias de montaje, descubrir nuevos sentidos que amplíen y complejicen las relaciones que se establecen con estas imágenes, otorgándoles un carácter polisémico que rebasa sus usos y significaciones primarias.

Si bien la imagen doméstica se produce principalmente desde y para la familia, una parte importante de estos archivos ha rebasado la esfera de lo privado y se ha incorporado al amplio universo de imágenes que 
circulan a través de internet. Esto se debe no sólo a que ahora los dispositivos con que se producen las imágenes estén vinculados a su distribución en red, sino también a lo que Lev Manovich (2005, 72-75) denomina representación numérica, que no significa más que el proceso de transferencia de un medio análogo a uno digital, es decir, la incorporación de un código numérico que permite que cada objeto (imagen, sonido, texto) sea representado por una función matemática susceptible de ser programada. Esta digitalización ha permitido poner en circulación un sinnúmero de archivos familiares anónimos y/o huérfanos (Cherchi Usai 1999) que antes permanecían ocultos o resguardados, ya sea al interior de los hogares o en colecciones de particulares, y que ahora pueden encontrarse y descargarse a través de la red. Eric de Kuyper (en Lins 2017, 48) afirma que los filmes domésticos cambian de estatuto cuando son depositados en un archivo público, pasando de ser souvenirs familiares destinados al consumo íntimo y particular, a constituir fragmentos de memoria colectiva que dan testimonio de un tiempo, una época y de otras formas de vida.

Entonces, el hecho de trabajar con imágenes familiares propias y/o ajenas supone un desplazamiento del ámbito privado al público. Un desbordamiento de la función original del archivo íntimo que pasa a integrarse al mundo de las imágenes, adquiriendo una dimensión política (Catalá, citado en Lins 2017, 47) que, bajo sus propios medios y organización simbólica, propone una reflexión crítica de lo social al exponer el artificio del orden impuesto que intenta presentarse como natural, permitiendo la emergencia de nuevas subjetividades, formas y modos de enunciación que anteriormente habían sido negadas, ocultadas y silenciadas (Capasso y Bugnone 2016, 134). Estas propuestas, por lo tanto, han sido parte medular del cine de reapropiación.

\section{Las ausencias en dos cortometrajes}

Para aterrizar algunas ideas teóricas planteadas arriba, nos centramos ahora en dos cortometrajes mexicanos realizados a partir de la reapropiación de archivos familiares, que permiten ilustrar las diferentes relaciones que sus realizadores guardan con respecto de las imágenes. Esto se establece como una variante fundamental en el proceso de elaboración de las películas, vinculada con las iteraciones de ausencia-presencia exploradas anteriormente. Se trata, de manera 
sintética, de dos películas presentadas en el festival ULTRAcinema, en las ediciones 2018 y 2019, respectivamente: ¡Allá Vienen!, dirigido por Ezequiel Reyes, y Fantasmas del adiós, dirigido por Ximena Cuevas. ${ }^{12}$

Fantasmas del adiós (2019) es una pieza íntima, de atmósfera nostálgica y espectral que transcurre entre los afectos, la memoria, el olvido, lo fantasmal y la muerte. Está realizada a partir de breves fragmentos fílmicos que se mezclan con imágenes de video y fotográficas. El desarrollo de la película ronda alrededor de la figura del padre de la autora, el pintor mexicano José Luis Cuevas, fallecido en 2017 (imagen $1)$.

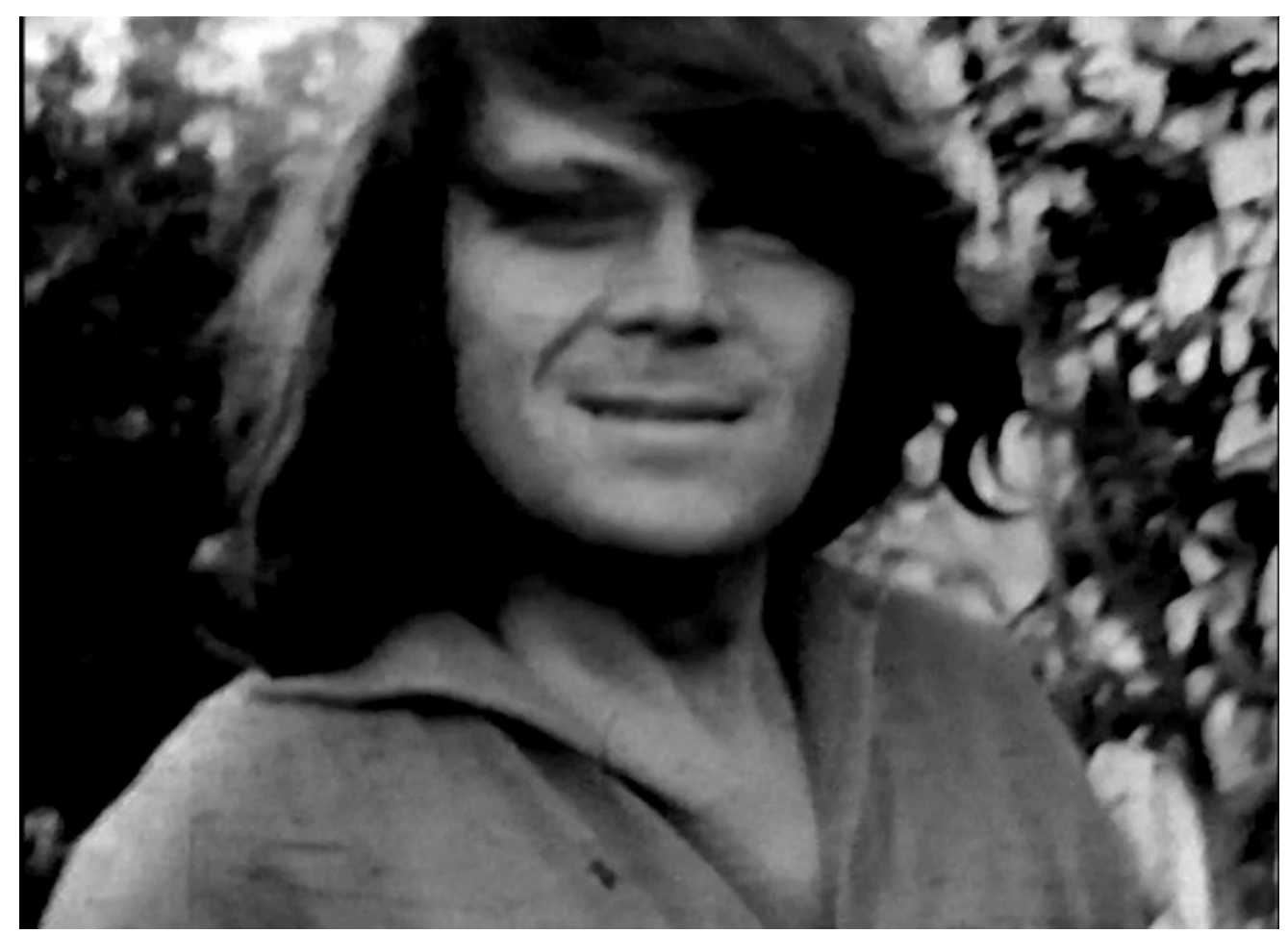

Imagen 1: Fotograma de Fantasmas del adiós (2019). | ๔ Ximena Cuevas.

A través de diversas técnicas de montaje, la realizadora logra trasmitir una sensación de evanescencia, en la que las imágenes devienen en presencias borrosas que funcionan como huellas de lo que alguna vez

\footnotetext{
${ }^{12}$ ULTRAcinema, que empezó hace una década como un foro de reapropiación, actualmente se presenta como "escaparate para el cine experimental, de found footage y en general al cine que le interesa una interacción profunda con el archivo audiovisual” (https://expcinema.org/site/es/directory/ultracinema), siendo uno de los espacios más importantes en América Latina para este tipo de producción.
} 
fue, haciendo evidente la fragilidad de la existencia, la vulnerabilidad del recuerdo y lo fragmentario e incompleto de la memoria. Conforme la película avanza, la dislocación del tiempo se hace más evidente, lo cual provoca una sensación onírica que se refuerza mediante algunas estrategias de edición, como la manipulación de la velocidad de reproducción de la película, la doble exposición, la cámara lenta, la repetición, el uso de largas disolvencias y las transiciones a negro (fade out). Esta constante alteración de lo temporal comunica el deseo de Cuevas de romper con la lógica de la continuidad, por ejemplo, cuando se reproducen algunas secuencias en reversa, desmantelando así la relación causa-efecto y subvirtiendo la linealidad del tiempo progresivo. La memoria y el recuerdo se presentan como algo fragmentario, sin orden, a veces repetitivo y siempre difuso.

La película está realizada en blanco y negro. Además del material claramente familiar, hay planos en donde aparecen escenas del mar; en algún momento, la cámara se planta frente al patio de una casa cercado por un alambre, lo que imposibilita poder entrar. La toma a distancia retrata con nostalgia un espacio vacío, frío y desolado. Esta imagen se acompaña de un audio en el que se escucha el timbre de un teléfono que nunca se contesta, lo que acentúa aún más la idea de la ausencia. De hecho, el diseño sonoro refuerza la sensación de espectralidad que caracteriza a todo el cortometraje. Se trata de una mezcla de audio compuesta de diversos elementos, entre ellos fragmentos de una melodía interpretada por Toña La Negra, en la que destaca la presencia sonora del mar.

Desde el propio título, el corto se relaciona con la crítica espectral que, al decir de Ribas-Casasayas, tiene que ver con la "interrogación de la ausencia que se hace sentir, de presencias imperceptibles, de apelaciones transgeneracionales que refutan la representación ideológica del presente como momento estanco" (2019, 9), para insistir, como Rivera Garza, que los muertos siempre son parte del escenario $(2013,287)$. La propuesta de Cuevas funciona como acto evocativo de la memoria; es un intento de hacer presente al ausente a través del medio audiovisual, en que la presencia resulta efímera y frágil. Aquí lo familiar no se limita a la representación del recuerdo feliz y nostálgico, sino que adquiere otra dimensión que rebasa esos usos tradicionales, trastocando las convenciones sobre lo que debe o no ser mostrado. La inclusión de una fotografía que muestra al padre recostado en la cama de un hospital permite pensar en los límites de lo 
que tradicionalmente se ha conceptualizado como imagen familiar. Al mismo tiempo, la decisión de hacer visible la agonía del ser querido permite, de alguna manera, a la directora exorcizar el dolor y aceptar la pérdida como una condición fatídica inherente a la existencia. En Fantasmas del adiós, la vida, la muerte, el recuerdo y la memoria se revelan como huellas difusas, plasmadas en celuloide en inútil desafío del inquebrantable devenir del tiempo.

En contraste al archivo personal usado en Fantasmas del adiós, iAllá vienen! (Ezequiel Reyes, 2018) fue realizado principalmente a partir del reempleo de fragmentos fílmicos que no guardan relación directa con el realizador. En su mayoría, se trata de imágenes de tipo familiar, aunque también se incluyen otras que podríamos considerar imágenes de aficionado que no se avocan a registrar lo familiar, sino la vida cotidiana. Con excepción de una escena, toda la película está constituida con material cuyo soporte original es fílmico, ya sea de 16 $\mathrm{mm}, 8 \mathrm{~mm}$ o súper 8 . En general, son películas adquiridas por el director en mercados de segunda mano y tiendas de antigüedades.

En este corto aparecen principalmente niños y mujeres (imagen 2). La presencia de los hombres resulta escasa; regularmente son imágenes de fiestas infantiles, ceremonias religiosas, paseos, vacaciones y actividades recreativas. También hay imágenes en que se pueden observar bailables escolares, desfiles y ceremonias oficiales de carácter cívico-militar. Además, aparecen paisajes montañosos, jardines, albercas, espacios rurales y urbanos. 


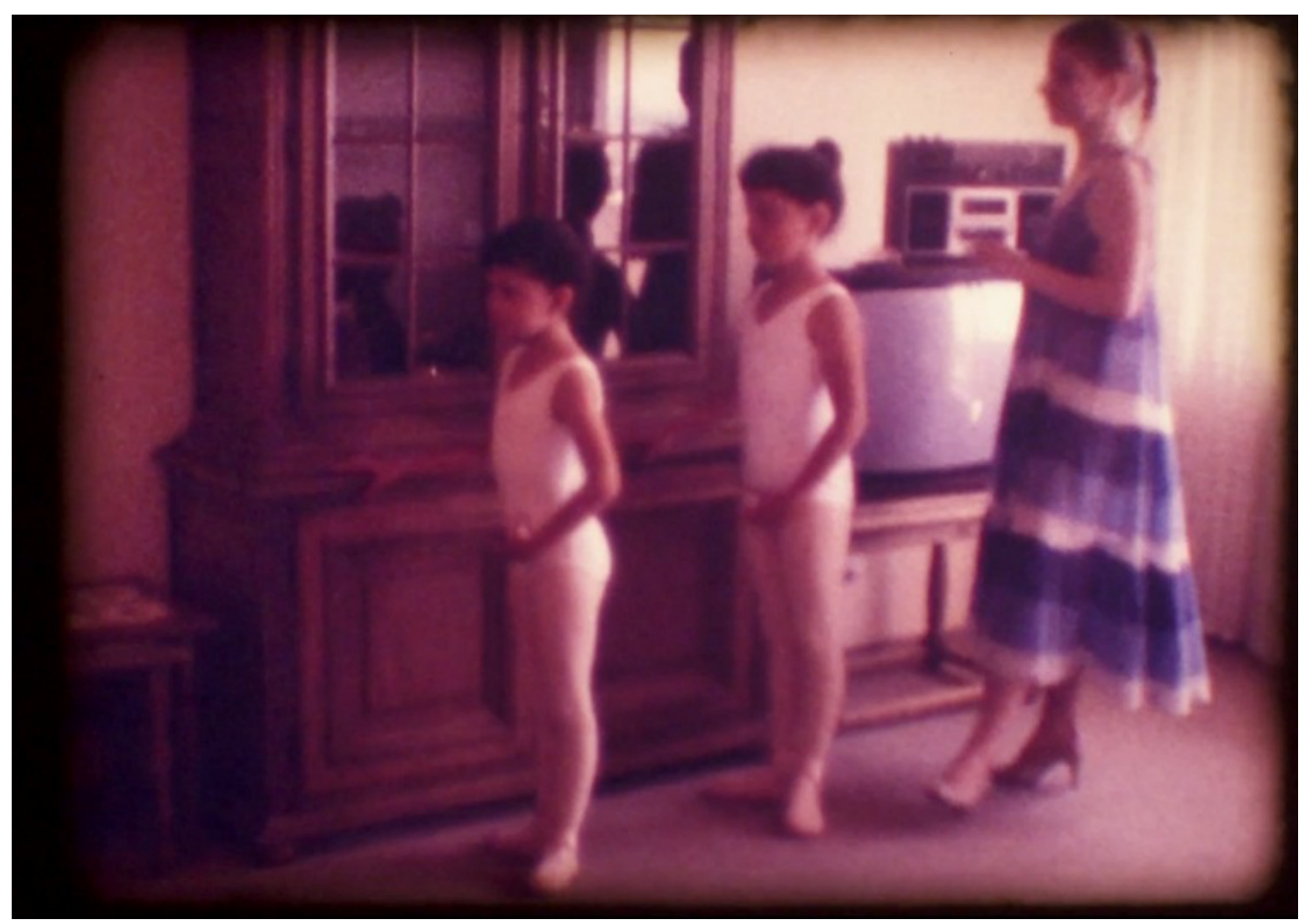

Imagen 2: Fotograma de ;Allá vienen! (2018). | @ Ezequiel Reyes.

Los protagonistas de las imágenes son familias mexicanas desconocidas y anónimas de las que no existe referencia alguna salvo lo que está en pantalla. En este sentido, su reutilización y puesta en circulación se manifiesta como un gesto que permite su reactivación, rescatándolas del olvido al que parecían estar destinadas. De este modo el material visual sale del anonimato y adquiere un nuevo sentido que ya no transita por lo personal y lo privado, sino que se sitúa en lo público y lo social.

El montaje de la película es sencillo y sobrio. No se imponen transiciones ni tampoco efectos; el encadenamiento de las secuencias se da por corte directo, y en ocasiones se utiliza la repetición de escenas, aunque no es una constante. La articulación de los fragmentos fílmicos se realiza sin una secuencialidad específica; en ocasiones parece seguir un ordenamiento a partir del contenido visual (un bloque de niños, un bloque de cumpleaños, un bloque de paseos, etc.), pero no lo suficiente para considerarlo como una estructura sobre la cual se desarrolle toda la película.

La multiplicidad de imágenes encuentra en el sonido su elemento cohesionador; es éste que establece el territorio narrativo común sobre el cual lo visible adquiere sentido. Se trata del poema "Los muertos" de 
María Rivera, recitado por su autora durante una manifestación en el zócalo de la Ciudad de México en 2011. En el poema se describen las sombras de un país azotado por la violencia, el dolor y la injusticia. La narración de Rivera es potente y cruda, tono que en todo momento contrasta con las imágenes visuales. Las tensiones que se generan por la oposición de los recursos narrativos (imagen/sonido) que emplea Reyes otorgan su potencia de la película permiten la resignificación de las imágenes, convirtiéndolas en metáforas extrañamente siniestras de un país que no existe más.

Hacia el final del cortometraje, aparecen algunas secuencias que ya no corresponden al imaginario familiar. Son imágenes que retratan algunos eventos de tipo nacionalista, como desfiles, ceremonias cívicas, actos a la bandera, etc. Aquí también Reyes incorpora una escena que ha sido grabada con cámara digital; es la única imagen que podríamos llamar, por su matriz tecnológica, actual. Es una secuencia con un breve corte en la que se puede apreciar la bandera mexicana rota y desgatada ondulando sobre una montaña de basura mientras un grupo de niños deambulan por el lugar. Es una bandera incompleta: le falta la parte correspondiente al color rojo, lo cual sugiere la metáfora de un país que se desangra, un país en ruinas. La escena que sigue contrasta con la anteriormente descrita, pues muestra un desfile en el que un grupo de cadetes marchan orgullosos con el lábaro patrio. Cuando estas secuencias aparecen en pantalla, el poema de Rivera ya ha finalizado, dejando una estela de angustia que se expande como un eco. Las imágenes transitan en silencio, lo cual aumenta su dramatismo y evidencia la intención del director de hacer con y de la película un discurso político crítico.

En el cortometraje de Reyes, lo familiar es despojado de su función de recuerdo personal e íntimo, y se instala en el terreno de la memoria colectiva, destacando la nostalgia por el pasado como un tiempo mejor en comparación con el presente visto como violento y cruel. En el poema de Rivera los ausentes se nombran, haciéndose presentes a través de la palabra, mientras que las imágenes reactivan los recuerdos olvidados de personajes anónimos que por alguna razón abandonaron sus memorias al incierto devenir del tiempo. 


\section{Reflexiones finales}

Aunque los cortometrajes comentados de ningún modo agotan las posibilidades del cine de reapropiación ni las formas en que éste se ha sido presentado en el festival ULTRAcinema y en otros foros incluyendo los medios informales representados por canales como YouTube, Vimeo, y redes sociales-, sí nos permiten volver al tema inicial del cine como ausencia, de la memoria a la resignificación. La película de Cuevas, asociada inevitablemente con un proceso de duelo que es a la vez privado y público, ${ }^{13}$ nos remite al poder del cine, no de fabricar o restaurar lo inexistente (lo ya-no-existente o la nuncaexistente), sino para reconocer y honrar a las ausencias: tarea que también corresponde a todas las manifestaciones culturales de lo espectral (Ribas-Casasayas 2019).

En cambio, iAllá vienen! parte desde imágenes "encontradas", anónimas, y las conjunta con la poesía para construir una fábula catastrófica de la nación: la antítesis, tal vez, del relato mítico ofrecido por los creadores de Tepeyac un siglo antes. Este método de abordaje de los archivos familiares se hace de la reapropiación una forma autoconsciente y colectiva vinculada con lo que Cristina Rivera Garza $(2013,2017)$ prefiere llamar la desapropiación, asociada con el hacer visible la labor tanto de quien arma la película (aunque ella habla de literatura), como de todos los seres involucrados en el hecho de su existencia. Este trabajo Rivera Garza relaciona con el tequio (labor colectiva obligatoria) y también con una vinculación con la muerte; el diálogo con los seres del pasado - llamado por la autora los muertos indóciles-vuelve parte del proceso de ubicación del trabajo en el momento presente, una obra situada, consciente de sus ausencias y de la "deuda impagable" que cualquier artista (o investigador/a) lleva a cuestas. "Cuando la desapropiación se propone sacar a la luz los lazos de deuda que atan a la escritura con los practicantes de una lengua", escribe Rivera Garza, "lo que hace en realidad es impagarla" (2017). De la misma manera, quienes hacen cine de reapropiación hacen visibles las ataduras del archivo visual a las estructuras políticas, sociales, económicas y culturales dentro de las cuales determinadas imágenes, y sólo ellas, no se convierten en cenizas.

\footnotetext{
${ }^{13}$ José Luis Cuevas falleció en julio de 2017, una muerte aún reciente cuando se estrenó Fantasmas del adiós.
}

aniki A Pesquisa Histórica no Cinema Latino-Americano | Historical Research in Latin-American Cinema 


\section{Referencias}

Aguirre, Carlos, y Villa-Flores, Javier. 2015. From the Ashes of History: Loss and Recovery of Archives and Libraries in Modern Latin America. Raleigh, NC: Editorial A Contracorriente.

Amador, María Luisa, y Ayala Blanco, Jorge. 2009. Cartelera cinematográfica 1912-1919. México: Universidad Nacional Autónoma de México.

Benjamin, Walter. 2003. La obra de arte en la época de su reproductibilidad técnica. México: Itaca.

Bernini, Emilio. 2010. "Found footage: lo experimental y lo documental”. En ¿Qué es y a dónde va el found footage?, compilado por Leandro Listorti y Diego Trerotola, 25-38. Buenos Aires: Buenos Aires Festival Internacional de Cine Independiente (BAFICI).

Bourriaud, Nicolás. 2004. Post producción: la cultura como escenario: modos en que el arte reprograma el mundo contemporáneo. Buenos Aires: Adriana Hidalgo Editora.

Capasso, Verónica, y Bugnone, Ana. 2016. “Arte y política: un estudio comparativo de Jacques Rancière y Nelly Richard para el arte latinoamericano". Hallazgos 26: 117-148.

Cherchi Usai, Paolo. 1999. "What is an Orphan Film? Definition, Rationale Controversy". Ponencia presentado en el simposio Orphans of the Storm: Saving 'Orphan Films' in the Digital Age, Columbia: University of South Carolina, 23 de septiembre de 1999.

http://www.sc.edu/filmsymposium/archive/orphans2001/usai. $\underline{\mathrm{html}}$

Cosentino, Olivia, y Price, Brian, eds. 2022 (en prensa). The Lost Cinema of Mexico: From Lucha Libre to Cine Familiar and Other Churros. Gainesville: University of Florida Press.

Cuarterolo, Andrea. 2017. "El archivo en la época de su reproductibilidad técnica. Recursos digitales para el estudio del cine silente latinoamericano". Vivomatografías. Revista de estudios sobre precine y cine silente en Latinoamérica 3(3): 416-447. http://www.vivomatografias.com/index.php/vmfs/article/view $\angle 143$ 
De los Reyes. Aurelio. 1981. Cine y sociedad en México, 1896-1930, tomo I, Vivir de sueños (1896-1920). México: Universidad Nacional Autónoma de México.

-_- 1986. Filmografía del cine mudo en México, 1896-1920. México: Filmoteca de la UNAM.

_-_. 1987. Medio siglo de cine mexicano (1896-1947). México: Trillas.

_-_. 1993. Cine y sociedad en México, 1896-1930, vol. II, Bajo el cielo de México (1920-1924). México: Universidad Nacional Autónoma de México.

-_- 2016. "Del cine mudo al sonoro". En Miradas al cine mexicano, vol. 1, coordinador por de los Reyes García-Rojas. México: Instituto Mexicano de Cinematografía, Secretaría de Cultura.

De los Reyes, Aurelio, y M. L. Wood, David. 2016. “Introducción”. En Cine mudo latinoamericano: inicios, nación, vanguardias y transición, coordinado por de los Reyes y Wood, 9-19. México: Universidad Nacional Autónoma de México.

Didi-Huberman, Georges. 2012. Arde la imagen. Oaxaca: Ediciones Ve, Fundación Televisa.

Elsaesser, Thomas. 2015. "La ética de la apropiación: found footage, entre el archivo e internet”. Found Footage Magazine 1: 119-123.

García Riera, Emilio. 1992. Historia documental del cine mexicano. Guadalajara: Universidad de Guadalajara, IMCINE.

Groo, Katherine. 2019. Bad Film Histories: Ethnography and the Early Archive. Minneapolis: University of Minnesota Press

Guardiola, Ingrid. 2015. La imagen dialéctica en el audiovisual found footage: un hiperarchivo de conceptos visuales. Tesis de doctorado. Barcelona: Universidad Pompeu Fabra.

Hernández, Manuel, y Martín, Juan Luis. 1998. “La recepción de la obra de arte y la participación del espectador en las propuestas artísticas contemporáneas”. REIS: Revista Española de Investigaciones Sociológicas: 45-63.

Leal, Juan Felipe. 2019. Filmografía mexicana: 1896-1911. México: Juan Pablos Editor.

-—-. 2012. El documental nacional de la Revolución Mexicana: filmografía, 1915-1921. México: Juan Pablos Editor. 
Leal, Juan Felipe, Barraza, Eduardo y Jablonska, Alejandra. 1993. Vistas que no se ven: filmografía mexicana, 1896-1910. México: Universidad Nacional Autónoma de México.

Lerner, Jesse, y Piazza, Luciano, eds. 2017. Ismo, ismo, ismo. Cine experimental en América Latina / Ism, Ism, Ism: Experimental Cinema in Latin America. Oakland: University of California Press.

Lins, Consuelo. 2017. "Films de familia, cine amateur y la memoria del mundo". Arkadin 6: 45-62.

Manovich, Lev. 2005. El lenguaje de los nuevos medios de comunicación. La imagen en la era digital. Barcelona: Paidós.

Martín, Juan Luis. 2001. La apropiación posmoderna. Arte, práctica y teoría de la posmodernidad. Madrid: Fundamentos.

Miquel, Ángel. 2000. Mimi Derba. México: Archivo Fílmico Agrasánchez.

-_- 2003. Un pionero del cine en México. Salvador Toscano y su colección de carteles. México: Fundación Carmen Toscano.

-_-. 2005. Acercamientos al cine silente mexicano. Cuernavaca: Universidad Autónoma del Estado de Morelos.

-_- 2012. En tiempos de revolución. El cine en la ciudad de México (1910-1916). México: Universidad Nacional Autónoma de México.

Ortiz Monasterio, Pablo (ed.). 2010. Fragmentos. Narración cinematográfica compilada y arreglada por Salvador Toscano, 19001930. México: Conaculta/ Imcine/ Universidad de Guadalajara.

Mraz, John. 2003. “¿Qué tiene de nuevo la historia gráfica?” Diálogos. Revista do Departamento de História (Universidade Estadual de Maringá) 7: 201-217.

Noriega, Eva. 2012. "Notas sobre found footage”. Arte e Investigación 8: 136-139.

Pérez Montfort, Ricardo. 2011. "Escribir historia con imágenes. Breve relato de tres experiencias”. En Estudiando imágenes. Mirados múltiples, coordinado por Victoria Novelo Oppenheim, 33-47. México: Centro de Investigaciones y Estudios Superiores en Antropología Social (CIESAS). 
Rancière, Jacques. 2008. "El teatro de las imágenes”. En Alfredo Jaar: la política de las imágenes, ed. Adriana Valdés B., 69-89. Chile: Metales Pesados.

Ribas-Casasayas, Alberto. 2019. "El espectro, en teoría”. iMex. México Interdisciplinario. Interdisciplinary Mexico, 8(16): México Espectral (ed. Ribas-Casasayas): 8-20. https://www.imexrevista.com/ediciones/xvi-mexico-espectral/

Rivera Garza, Cristina. 2013. Los muertos indóciles. Necroescrituras y desapropiación. México: Tusquets.

-_-. 2017. "Desapropiación para principiantes". Literal. Latin American Voices/Voces Latinoamericanas, 31 de mayo de 2017. https://literalmagazine.com/desapropiacion-para-principiantes/

-_- 2020. The Restless Dead: Necrowriting and Disappropriation. Nashville: Vanderbilt University Press.

Russo, Eduardo. 2016. "La mirada del cine en la sociedad de control. Vigilancia, found footage y resistencia”. Arkadin 5: 20-36.

Serrano, Alicia. 2013. "Apropiacionismo, remezcla y postproducción: el Found Footage en el siglo XXI”. En Estéticas del Media Art, coordinado por José Luis Crespo Fajardo, 15-35. Málaga: Grupo de investigación Eumed.net, Universidad de Málaga.

Sontag, Susan. 2010. Sobre la fotografía. México: Gandhi.

Soto, Jessica. 2020. "En 1982, parte de la historia se borró con el incendio de la Cineteca Nacional". El Universal, 12 de septiembre de 2020. https://www.eluniversal.com.mx/cultura/parte-de-lahistoria-se-borro-con-el-incendio-de-la-cineteca-nacional-en$\underline{1982}$

Talens, Jenaro, y Zunzunegui, Santos. 1998. "Introducción: por una verdadera historia del cine". En Historia general del cine. Vol. I: Orígenes del cine, coordinado por Talens y Zunzunegui, 9-38. Madrid: Cátedra.

Torres San Martín, Patricia. 2018. Elena Sánchez Valenzuela. Guadalajara: Universidad de Guadalajara, Cineteca Nacional.

Trerotola, Diego. 2010. "Post-cine". En Cine encontrado. ¿Qué es y a dónde va el found footage?, compilado por Leandro Listorti y Diego Trerotola, 51-64. Buenos Aires: Buenos Aires Festival Internacional de Cine Independiente (BAFICI). 
Vázquez Mantecón, Álvaro. 2017. "Experimentación visual en Super 8: México y América Latina”. En Ismo, ismo, ismo. Cine experimental en América Latina / Ism, Ism, Ism: Experimental Cinema in Latin America, editado por Jesse Lerner y Luciano Piazza, 26-49. Oakland: University of California Press.

Vilches, Gloria. 2009. "Usos, estilos y formatos contemporáneos del audiovisual de apropiación en España". Investigación Montehermoso: 1-77.

Wasson, Haidee. Everyday Movies: Portable Film Projectors and the Transformation of American Culture. Oakland: University of California Press, 2020.

Weinrichter, Antonio. 1998. "Subjetividad impostura apropiación: En la zona donde el documental pierde su honesto nombre". Filmoteca 30: 108-123.

-_- 2009. Metraje encontrado. La apropiación en el cine documental y experimental. Navarra: Gobierno de Navarra, Departamento de Cultura y Turismo, Institución Príncipe de Viana.

Wolf, Sergio. 2010. “El manantial”. En Cine encontrado. ¿Qué es y a dónde va el found footage? compilado por Leandro Listorti y Diego Trerotola, 11-16. Buenos Aires: Buenos Aires Festival Internacional de Cine Independiente (BAFICI).

Wood, David. 2011. “Cine mudo, ¿cine nacional?” En México imaginado. Nuevos enfoques sobre el cine (trans) nacional, coordinado por Claudia Arroyo Quiroz, James Ramey y Michael K. Schluesser, 29-52. México: Universidad Autónoma Metropolitana.

- - - 2014. "Vestigios de historia: el archivo familiar en el cine documental y experimental contemporáneo". Anales del Instituto de Investigaciones Estéticas UNAM 104: 97-125.

\section{Filmografía}

El automóvil gris [largometraje]. Dir. Enrique Rosas. Azteca Films / Rosas y Cía., México, 1919. Duración variable: 3 horas, 43 min en la versión restaurada (2019).

Fantasmas del adiós [cortometraje, en línea]. Dir. Ximena Cuevas. Archivos X, México, 2019. 5 min. https://vimeo.com/346277628 (consultado 06/10/2021). 
La historia en la mirada [documental, en línea]. Dir. José Ramón Mikelajáuregui. Dirección General de Actividades Cinematográficas de la UNAM / Filmoteca de la UNAM / Instituto Nacional de Antropología e Historia / Guadalupe Ferrer / José Ramón Mikelajáuregui, México, 2010. 78 min. https://www.filmoteca.unam.mx/cine-en-linea/la-historia-en-lamirada/ (consultado 06/10/2021).

Los rollos perdidos [documental]. Dir. Gibrán Bazán. Marsash Producciones / Xibalba Films, México, 2012. 90 min.

Los rollos perdidos de Pancho Villa [documental]. Dir. Gregorio Rocha. Archivia Films / Banff Center For The Arts / Universidad Autónoma de Guadalajara, México, 2003. 49 min.

¡Allá vienen! [cortometraje, en línea]. Dir. Ezequiel Reyes. Archivo Fílmico Reyes, México, 2018. 8 min. https://www.filminlatino.mx/corto/alla-vienen (consultado 06/10/2021).

Tepeyac [largometraje, en línea]. Dir. Carlos E. Gonzáles, José Manuel Ramos y Fernando Sáyago. Films Colonial, México, 1917. 63 min. https://www.filmoteca.unam.mx/cine-en-linea/cinesilente/tepeyac/ (consultado 06/10/2021).

\title{
Memória e Resignificação: Aproximações ao cinema de reapropriação no México
}

\begin{abstract}
Este artigo explora as possibilidades analíticas do estudo do cinema mexicano desde o desaparecimento e/ou fragmentação dos arquivos primordiais até ao exercício experimental de reconstrução. Baseamo-nos no crescente corpus de histórias trabalhadas das margens da cultura e da comunicação, onde as lacunas e os silêncios falam tanto como factos verificáveis. Partimos da perda da maior parte do arquivo cinematográfico mexicano do período mudo, refletindo que, mesmo em períodos posteriores, a ausência física dos muitos filmes perdidos ou destruídos é exacerbada por vários tipos de esquecimento. À medida que o acesso às tecnologias de produção se generalizou na segunda metade do século XX, verificou-se uma abundância de vestígios desligados de contextos identificáveis e, por conseguinte, dissociados tanto da memória individual como coletiva. São estas imagens incompletas, dispersas e residuais que o cinema de reapropriação utiliza para propor uma espécie de reordenamento simbólico: um exercício crítico de investigação sobre a imagem cinematográfica, os seus suportes materiais e os dispositivos que lhe dão origem. Para exemplificar os argumentos, analisamos as curtas-metragens Fantasmas
\end{abstract}


del adiós, de Ximena Cuevas (2019), e ¡Allá vienen! de Ezequiel Reyes (2018), ambos realizados a partir de arquivos familiares, que nos permitem ilustrar as diferentes estratégias possíveis para a ressignificação das memórias individuais e coletivas no atual cinema de reapropriação.

KEYWORDS Reapropriação; cinema experimental; cinema primitivo; cinema mexicano; história do cinema.

\section{Archive, Memory, and Resignification: Regarding the cinema of reappropriation in Mexico}

RESUMO This article explores the analytical possibilities of the study of Mexican cinema starting from the disappearance and/or fragmentation of primordial archives, concluding with the experimental exercise of reconstruction. We draw on the growing body of research about and from the margins of culture and communication, where gaps and silences speak as much as existent historical evidence. Beginning with the loss of most of the Mexican film archive from the silent era, we note that the physical absence of lost or destroyed films is exacerbated by various kinds of oblivion, even in later periods. However, as access to production technologies increased in the second half of the twentieth century, so too the abundance of traces detached from identifiable contexts and thus disassociated from both individual and collective memory. It is these incomplete, dispersed, and residual images that the cinema of reappropriation uses to propose a symbolic reordering: a critical engagement with the filmic image, its material supports and contexts. To exemplify our argument, we discuss the short films Fantasmas del adiós by Ximena Cuevas (2019) and iAllá vienen! by Ezequiel Reyes (2018), both made from family archives (home movies). These allow us to illustrate different possible strategies for the resignification of individual and collective memories in contemporary cinema of reappropriation.

PALAVRAS-CHAVE Reappropriation; experimental cinema; early cinema; Mexican cinema; film history.

Recebido a 14-07-2021. Aceite para publicação a 28-10-2021. 